\title{
Assessing the power of the point-line transect to monitor changes in plant basal cover
}

\author{
WARD W. BRADY, JOHN E. MTTCHELL, CHARLES D. BONHAM, AND JOHN W. COOK
}

\begin{abstract}
Authors are professor, Dept. of Planning (Environmental Resources), Arizona State University, Tempe 85287-2005; range scientist, USDA Forest Service, Rocky Mountain Forest and Range Experiment Station, Fort Collins, Colo. 80524; professor, Rangeland Ecosystem Science, Colorado State University, Fort Collins 80523; and research assoc., Dept. of Planning (Environmental Resources), Arizona State University, Tempe 85287-2005.
\end{abstract}

\begin{abstract}
To assess the power of point data (collected systematically at each meter along a permanently-situated, 100-m line transect) to detect actual changes in plant basal cover, we developed a computational approach whereby a simplified shortgrass steppe community was spatially simulated on a computer screen. Cover was then reduced using a random disturbance pattern. One transect could detect an actual decrease in cover from $12 \%$ to $8 \%$ with less than $20 \%$ probability, while 5 transects increased this power to about $80 \%(P \leq 05)$. A reduction in cover from 12 to $6 \%$ could be detected with $80 \%$ probability with only 2 transects, while a cover reduction to $10 \%$ could only be detected with $40 \%$ probability using 10 transects $(P \leq .05)$. Artificial populations provide a valuable mechanism for quantitatively evaluating field sampling designs.
\end{abstract}

Key Words: Short-grass steppe, vegetation measurement, Type II error, sample size, hypothesis testing, basal cover, disturbance.

The purpose of vegetation monitoring is to determine if significant ecologically important changes have occurred over time. It is also important to differentiate between ecological importance and statistical significance (Yoccoz 1991). To avoid such a misunderstanding, monitoring designs should clearly specify what constitutes an ecologically important vegetation change, and monitoring methods must be selected so that changes of this magnitude can be observed with acceptable error rates.

Acceptable error rates, themselves, should be a function of the ecological consequences of change, as has been noted in the evolving concept of ecological risk assessment (U.S. Environmental Protection Agency 1992). If vegetation changes have large relative ecological importance (or large implications for management), then acceptable error rates must be smaller than when changes have lesser consequences.

Monitoring designs should be stable, powerful, robust, and cost-effective if they are to detect ecologically important vegetation changes with acceptable error (Larsen and Marx 1981). Stable designs have an acceptable risk of a false conclusion of vegetation change; that is, Type-I statistical error is acceptable.

Manuscript accepted 15 Sept. 1994.
Powerful designs have an acceptable likelihood of detecting vegetation change, given known rates of Type-I error; that is, Type-II statistical error is acceptable. Robust methods are those that produce data that are not influenced by extraneous factors (Whysong and Brady 1987). For example, frequency is not a robust measure because it is dependent on plant size and shape (Bonham 1989). Lastly, cost-effective methods are those sufficient to meet these 3 criteria within available funding limitations.

The monitoring problem in natural resource management is one of how to design stable, powerful, robust, and economical inventory methods that will detect ecologically important changes with acceptable error rates. Several characteristics of the monitoring problem, including selection of desired magnitude of change to detect and acceptable risks of Type-I error, have been widely addressed (Cook and Stubbendieck 1986). Estimating the power of different methods, on the other hand, has been considered infrequently because doing so is infeasible using traditional field experiments. The cost of creating treatments is high and numerous replications are needed to ensure adequate replication.

One approach for studying Type-II error rates of monitoring designs is by employing simulation models with known distributions. Our objective was to evaluate point data from line transects, called point-line (Bonham 1989), with respect to power, using this procedure. The qualitative merits of point-line sampling are outlined in texts on vegetation sampling (Heady et al. 1959).

\section{Methods}

A rigorous evaluation of the point-line transect technique for monitoring changes in basal cover requires large sample sizes and known values of cover and the spatial distribution of plants, as well as plant sizes (Bonham 1989). Investigations based on field data are formidable and costly. Thus, computer simulations (Turbo Pascal, version 6.0) were used because they allowed controlled measurements of known population values with a large number of replications.

Graphic computer models were developed to represent both the point-line transect sampling method and vegetation characteristics of a representative shortgrass plant community situated at the U.S. Army's Pinon Canyon Maneuver Site, about $60 \mathrm{~km}$ northeast of Trinidad, Colo. (Shaw et al. 1989). For simulation purpos- 
es, the community was defined in terms of the dominant species, blue grama (Bouteloua gracilis (H.B.K.)Lag.), with an initial basal cover of $12 \%$. Plant shape was assumed to be circular. Two mean plant sizes, 8 and $12 \mathrm{~cm}$ in diameter, were used to parameterize the simulated community, but no statistical differences were found between them and the data were combined (Mitchell et al. 1994).

Simulated communities were initially created that had random, moderately-, and highly-contagious distributions. Both random and nonrandom disturbance patterns were likewise evaluated. However, preliminary analyses showed that no significant differences were caused by plant distribution or disturbance pattern, at scales considered in these analyses, and only the randomly distributed communities were used in this study (Mitchell et al. 1994). Disturbance treatment effects were combined.

The effect of disturbance was assumed to be one-tailed. That is, military commanders (not unlike other rangeland managers) are primarily concerned about monitoring whether abundance of beneficial vegetation has decreased from that found on sites in satisfactory condition. Once a site has been placed in an undesirable state, the manager would be interested in monitoring the success of recovery efforts, another 1-tailed test. A 1-sided hypothesis provides an advantage over a 2 -sided test if values in only 1 direction from $\mathrm{H}_{\mathrm{O}}$ are meaningful because its critical value is closer to the population mean (Larsen and Marx 1981), thus increasing the test's power.

The concept of a management objective based upon 2 condition states, satisfactory and unsatisfactory, is almost 50 years old (Ellison 1949), but is the focus of renewed interest in terms of warning lines between healthy and at-risk states of rangeland health (Committee on Rangeland Classification 1994). Of course, when more than 2 condition states are possible, and movement can be in both directions, a 2-tailed test is appropriate.

A scale of $1 \mathrm{~cm}^{2}$ per pixel was used to generate vegetation models and cover measurements. At this scale, each graphic screen represented a community of 10.24 by $7.68 \mathrm{~m}$. Therefore, a simulated vegetation community large enough for inclusion of a 100-m transect was represented by 11 separate, but linked, graphic screens.

All simulation trials began with the initial population cover value of $12 \%$. Binomial (hit-miss) data were recorded from 100 points systematically located at $1-\mathrm{m}$ intervals along transects following the procedure described for training lands under control of the U.S. Army (Tazik et al. 1992).

The simulation model used 1 computer screen pixel to represent a sample point. Such an approach facilitated basal cover estimation because observations were always dichotomous; that is, each pixel was either totally covered by a plant or is not covered at all. This corresponds to the assumed field situation in which the point is dimensionless, thereby providing nominal-scale data fitting a binomial distribution.

Ten thousand randomly located permanent transects from each of 10 independent simulated blue grama populations with the same cover (12\%) were used to obtain estimates of basal cover. The populations were then reduced in basal cover by removing individual, random plants. Each new population was sampled for basal cover using the same 10,000 permanently located transects. The disturbance and resampling process was repeated until reduced populations of $10 \%, 8 \%, 6 \%, 4 \%$, and $2 \%$ were obtained.

The power of the point-line transect method was estimated using 10 different sample sizes (numbers of transects grouped into a sample), ranging from $n=1$ to $n=10$. Grouping of transects assumed homogeneity among simulated communities.

Precision of basal cover estimates was estimated using confidence intervals derived directly from distributions of 10,000 sample replicates for each set of estimates. Areas under distribution curves from sampling-disturbance-resampling iterations were then directly measured to estimate the power of the technique to detect reductions in basal cover for each vegetation condition (Tanke and Bonham 1985). Power curves were used to summarize these data.

\section{Results and Discussion}

\section{Accuracy and Precision}

Sample means of plant basal cover were estimated with an accuracy of less than $0.5 \%(P \leq 0.05)$ for simulated populations with a range of $2 \%$ to $12 \%$ basal cover. The high level of accuracy was obtained because sample means were calculated from extremely large samples relative to any sample collected in field studies.

Expectedly, as the number of transects grouped into a sample increased, the range in estimated mean cover decreased and the proportion of estimates falling closer to the true mean increased. For example, when 1 transect was used to estimate basal cover from the initial population (12\%), the estimates for $\mu$ ranged from $0 \%$ to $25 \%$ while approximately one-half of them fell between $10 \%$ and $14 \%$ (Fig. 1). If 10 transects were grouped, the range of estimates for the initial population narrowed to $0 \%$ to $17 \%$ and 19 out of 20 were within $\pm 2 \%$ of $12 \%$ (Fig. 2).

The resulting sampling distributions (1-tailed test) means a manager would have to estimate a basal cover of $\leq 6 \%$ before inferring that cover had decreased when using 1 transect, but would make the same judgment when cover decreased to $10 \%$ with 10 transects $(P \leq 0.05)$.

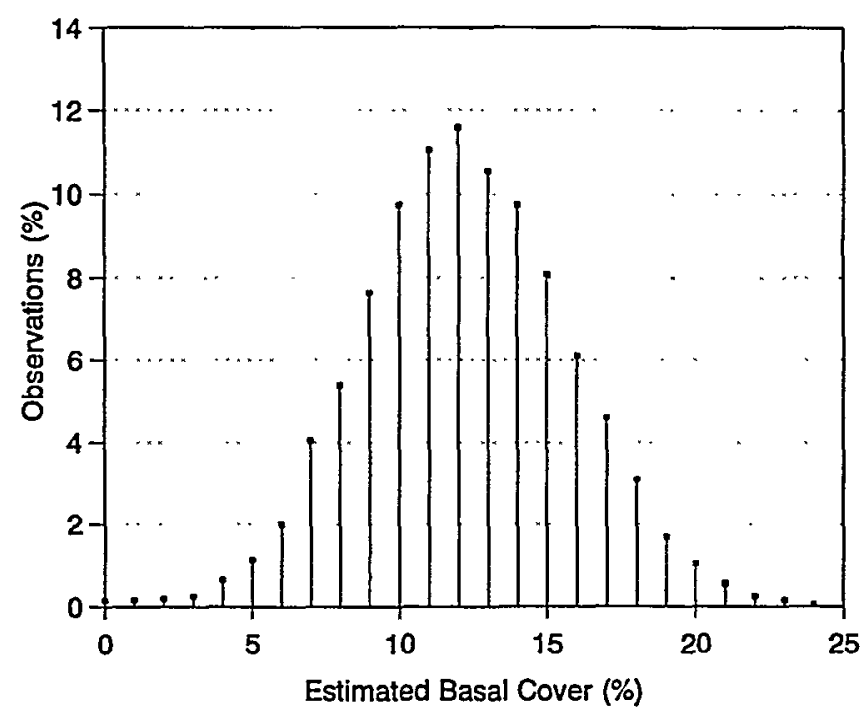

Fig. 1. Sampling distribution of basal cover estimates of a simulated blue grama population with a true population cover of $12 \%$. Derived from Monte Carlo analysis from a single $100-\mathrm{m}$, point-line transect (100 points). 


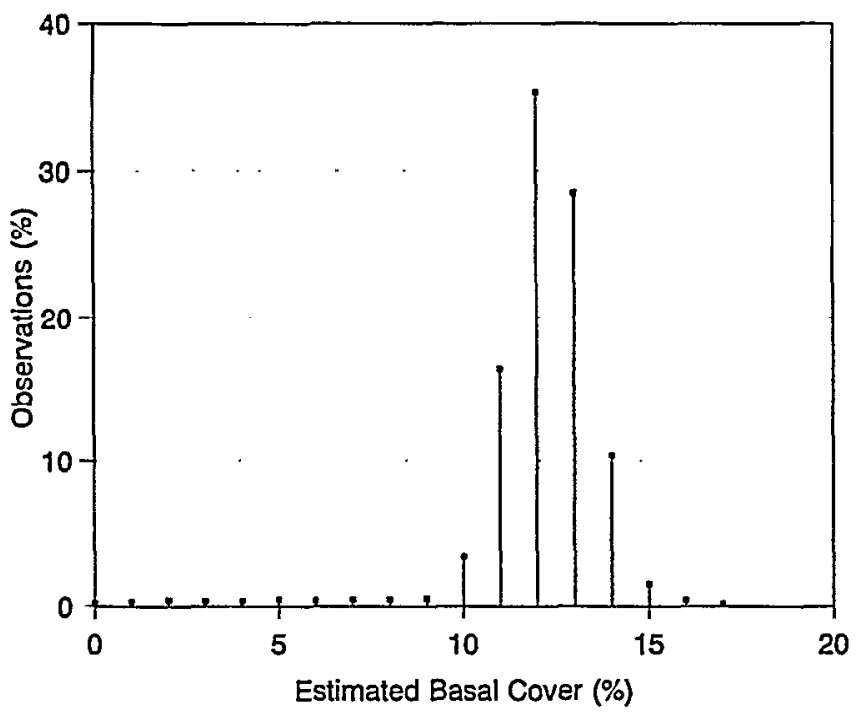

Fig. 2. Sampling distribution of basal cover estimates of a simulated blue grama population with a true population cover of $12 \%$. Derived from Monte Carlo analysis from three $100-\mathrm{m}$, point-line transects (100 points each). Cover values classified to nearest percent.

\section{Power}

The power of the monitoring design increased as the acceptable rate of Type-I error became larger, sample precision increased (expressed through increased sample size), and the minimum detectable change in basal cover increased.

Type-I Error. Consider the situation described above with an initial basal cover of $12 \%$ and a sample size of one transect, giving a rejection region of $\leq 6 \%$ cover for the probability of a TypeI error of $\alpha=.05$. Under these conditions the probability of detecting a $50 \%$ decrease in basal cover to $6 \%$ was $42 \%$ (Fig. 3). If the allowable Type-I error was increased to $\alpha=.086$, or about

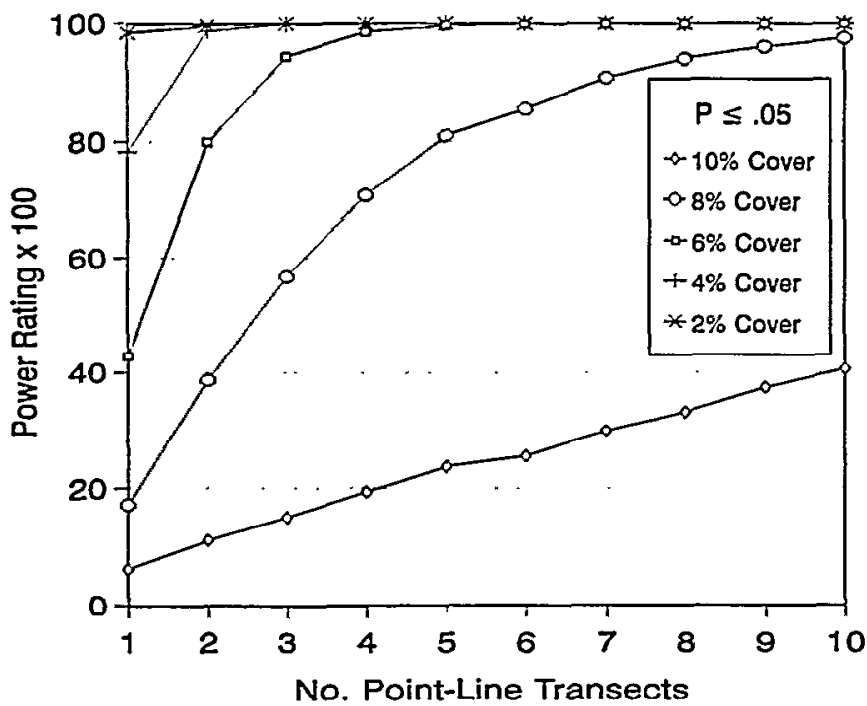

Fig. 3. Power curves for decreases in basal cover from a simulated blue grama population $(\mu=12 \%)$ to $10 \%, 8 \%, 6 \%, 4 \%$, and $2 \%$ cover. $P \leq 0.05$. Standard error of all means $\leq 0.5 \%$.

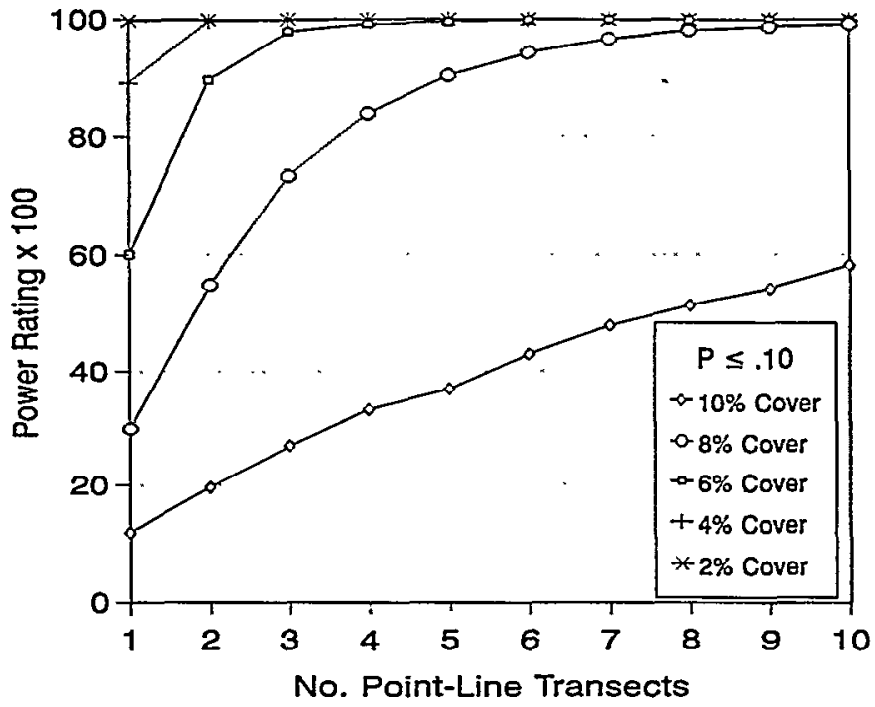

Fig. 4. Power curves for decreases in basal cover from a simulated blue grama population $(\mu=12 \%)$ to $10 \%, 8 \%, 6 \%, 4 \%$, and $2 \%$ cover. $P \leq 0.10$. Standard error of all means $\leq 0.5 \%$.

$10 \%$ for the null population (rejection region $\leq 7 \%$ basal cover), then the probability of detecting the same change increased to approximately $59 \%$ (Fig. 4). As the number of transects in the sample approached 5 , the differences in power due to varying acceptable level of Type-I error became much less important.

Sample Size. Sample size is an important consideration on military training lands because sample allocation of the Army's land condition analysis program is based upon population size (land area) rather than population variance (Tazik et al. 1992). As depicted in figures 3 and 4 , the power of the point-line method was plainly affected by the number of transects used to estimate basal cover. The relationship between power and sample size was logarithmic.

Minimum Detectable Change. As the degree of change to be detected increased, the power of the point-line method to distinguish it increased measurably. For instance, when 3 transects were grouped as a sample and given an acceptable Type-I Error of $\alpha=.05$, the power of detecting a $2 \%$ decrease in basal cover was less than $15 \%$, while the power of detecting a $4 \%$ change slightly greater than one-half. The loss of one-half of the original cover $(12 \%$ to $6 \%)$ could be discerned more than 9 times out of 10 (Fig. 3).

Of the variables affecting the power of the point-line method, only increased sample size requires greater cost to attain greater power. Its tradeoff is between cost-effectiveness and power rather than stability or sensitivity and power.

The logarithmic relationship between sample size and minimum acceptable detectable change, shown in Figures 3 and 4, provides some insight for those designing vegetation monitoring systems: That is, if relatively small changes in species abundance are important to observe, additional observations tend to equally increase the monitoring system's power. Thus, their value stays somewhat constant as the sample size increases. However, when larger changes in cover must occur before they can be detected, each added observation contributes less to the monitoring sys- 
tem's power.

For a given sample size, increasing the minimum acceptable detectable change will enhance statistical power to a greater extent than allowing the Type-I error probability to increase. Therefore, when planning a monitoring program, one will generally maximize the power of estimates from point-line data by allowing for the largest possible minimum detectable change.

\section{Conclusions}

Appropriateness of the point-line transect sampling design for monitoring changes in plant cover can be evaluated by considering power and robustness of the design given desired Type-I statistical error and the minimum detectable change. Careful thought should be given to the ecological consequences of both Type-I and Type-II statistical errors and appropriate rates of error then assigned. In some circumstances the ecological consequences of wrongly concluding change in cover when none has occurred (Type-I error) are equivalent to the consequences of failing to detect change (Type-II error). Under such conditions, the errors must be equally appraised in designing the monitoring system.

In evaluating monitoring designs, Type-I error rates are assigned based on knowledge of the baseline population and the ecological consequences of error. Type-II error rates are then determined by reference to the power curves generated from simulation models. Power curves are then used to determine sample sizes necessary to satisfy accuracy and risk requirements. Simulation modeling provides a way to select measurement and monitoring methodology for plant basal cover. Budgetary constraints usually are primary in dictating magnitudes of change possible to detect and error rates are often set without ecological considerations. Good monitoring practice, on the other hand, would dictate that ecological considerations have a major influence on error rates of a monitoring design.

Tools are now available to plan monitoring designs to ensure that the proper tradeoffs are made between Type-I error, power, desired detectable change, and sample size. Failure to use these tools may result in monitoring designs which are incapable of meeting monitoring objectives. Specifically, monitoring designs may not have a reasonable probability of detecting important ecological changes. Poorly planned monitoring designs will not provide decision makers the information they need to protect ecological resources. Properly designed monitoring systems, on the other hand, will provide the data that land managers require to respond to changes in ecosystems and help insure that wise management decisions are made.

\section{Literature Cited}

Bonham, C.D. 1989. Measurements for terrestrial vegetation. Wiley Intersciences, N.Y.

Committee on Rangeland Classification, Board on Agriculture, National Research Council. 1994. Rangeland health - new methods to classify, inventory, and monitor rangelands. National Academy Press, Washington, D.C.

Cook, C.W., and J. Stubbendieck. 1986. Range research: basic problems and techniques. Society for Range Management, Denver, Colo.

Ellison, L. 1949. The ecological basis for judging condition and trend on mountain range land. J. Forestry 47:786-795.

Heady, H.F., R.P. Gibbons and R.W. Powell. 1959. A comparison of the charting, line intercept, and line point methods of sampling shrub types of vegetation. J. Range Manage. 12:180-188.

Larsen, R.J., and M.L. Marx. 1981. An introduction to mathematical statistics and its application. Prentice-Hall, Inc. Englewood Cliffs, N.J.

Mitchell, J.E., W.W. Brady and C.D. Bonham. 1994. Robustness of the point-line method for monitoring basal cover. USDA Forest Service Res. Note RM-528. Rocky Mountain Forest and Range Experiment Station, Fort Collins, Colo.

Shaw, R.B., S.L. Anderson, K.A. Schulz and V.E. Diersing. 1989. Floral inventory for the U.S. Army Pinon Canyon Mancuver Site, Colorado. Phytologia 67:1-42.

Tanke, W.C., and C.D. Bonham. 1985. Use of power curves to monitor range trend. J. Range Manage. 38:428-431.

Tazik, D.J., S.D. Warren, V.E. Diersing, R.B. Shaw, R.J. Brozka, C.F. Bagley and W.R. Whitworth. 1992. U.S. Army land condition-trend analysis (LCTA) plot inventory field methods. USACERL, Tech. Rep. N92/03. Dept. of the Army. Construction Engineering Research Laboratory. Champaign Ill.

U.S. Environmental Protection Agency. 1992. Framework for ecological risk assessment. EPA/630/R-92/001. U.S. Environmental Protection Agency, Washington D.C.

Whysong, G.L., and W.W. Brady 1987. Frequency sampling and Type-II errors. J. Range Manage. 40:472-474.

Yoccoz, N.G. 1991. Use, overuse and misuse of significance tests in evolutionary biology and ecology. Bull. Ecol. Soc. Amer. 72:106-111. 